\title{
ALGUMAS NOTAS SOBRE BONECAS PARA MULHERES “NEGRAS” EM MAPUTO
}

\author{
Denise Ferreira da Costa Cruz \\ Universidade de Brasília, Distrito Federal, Brasil
}

\begin{abstract}
Resumo: Este artigo busca pensar o lugar que as bonecas ocupam na formação da subjetividade de mulheres "negras" moçambicanas. Tendo em vista que a indústria de brinquedos opta pela superprodução de bonecas "brancas" e loiras para crianças de vários pertencimentos "étnicos", paramos para refletir sobre as seguintes questões: que lugares as bonecas ocupam na vida de uma criança? De que forma elas operam na maneira como as meninas se relacionam com os próprios corpos e com seus cabelos? Quais as implicações para uma menina negra que tem somente bonecas loiras disponíveis para brincar? Seria esse brinquedo também um objeto de criação de distinção racial? Farei uma reflexão da infância a partir das experiências rememoradas de mulheres adultas. Trata-se, portanto, de um olhar em retrospectiva feito por meio de relatos e reminiscências de mulheres que já brincaram com bonecas.
\end{abstract}

Palovras-chave: Bonecas; Mulheres negras; "Raça".

\section{Introdução}

Nigéria, 2006. O nigeriano Taofick Okoya, antigo empresário de uma fábrica de plásticos em seu país, foi comprar um presente de aniversário para sua sobrinha e só encontrou bonecas "brancas"' nas lojas. Esse seria um evento comum para outros tantos nigerianos e não teria a repercussão que teve não fosse o fato de que tal episódio o levasse a refletir sobre o porquê da oferta desses brinquedos e, posteriormente, a criar uma marca de bonecas "negras" inspiradas na estética africana. Atualmente, a Queens of Africa, marca criada por ele, vende mais na Nigéria do que a famosa boneca Barbie. Em entrevista ao portal G1, a partir de sua vivência com a sua filha quando esta tinha três anos de idade, Okoya afirmou:

\section{c) (i) Esta obra está sob licença Creative Commons.}

' As categorias "branca" e "negra" serão aqui mencionadas entre aspas uma vez que são maleáveis, contextuais e relacionais. Embora o texto esteja permeado pela questão "racial", esta deve ser considerada apenas como um constructo social e não como realidade biológica. Dessa forma, a meu ver, não há como falar em branco sem aspas ou negro sem aspas sem essencializar seu uso. 
A ideia é promover a autoaceitação e a confiança nas crianças africanas e nigerianas. Queria que elas gostassem de si mesmas e de sua raça. Percebi que a superexposição a bonecas e personagens brancos fazia com que elas desejassem ser brancas. Os personagens preferidos dela eram todos brancos, as bonecas, também. Um dia ela [sua filha] me perguntou: 'de que cor eu sou?'. Disse que ela é negra e ela falou que preferiria ser branca. Tive que explicar que há tipos diferentes de pessoas e culturas no mundo, que não somos todos iguais, e que negro também é bonito. ${ }^{2}$

Sua fala explicita alguns aspectos importantes: autoaceitação, representatividade para as crianças nigerianas, "raça", identificação. Sua sensibilidade diante da angústia de uma criança levou-o a criar algo diferente, ousar, reverter uma realidade que estava colocada. A marca Queens of Africa apresenta seis modelos de bonecas representando as três maiores "etnias" da Nigéria: Hausa, Igbo e Yoruba. Observa-se que os cabelos e as roupas das bonecas baseiam-se em estilos de mulheres africanas. Elas estão envoltas em tecidos muito usados por mulheres africanas da África Ocidental e possuem tranças aplicadas em suas cabeças. Usam turbantes e têm a pele negra.

A falta de bonecas "negras" no mercado mundial é uma realidade que pode ser estendida a outros contextos africanos. Certamente, esses outros contextos apresentam singularidades e diferenças na recepção, aceitação e uso dessas bonecas. É preciso estar atenta a essas diferenças. Em uma incursão pelas lojas de brinquedos em Maputo, pude constatar que todas as bonecas, fossem elas representações de bebês ou de mulheres adultas, eram "brancas". Em entrevistas e conversas informais, realizadas em 2015, com minhas interlocutoras e com algumas crianças, elas mencionaram que bonecas negras eram raras no mercado de brinquedos durante a sua infância. Além disso, bonecas são objetos caros, são consumidos majoritariamente pela classe média que reside em Maputo. Os moradores das periferias são presenteados com brinquedos e bonecas de segunda mão.

Tendo em vista que a indústria de brinquedos coloca no mercado uma superprodução de bonecas "brancas" e loiras para crianças de vários pertencimentos "étnicos", paramos para refletir sobre as seguintes questões: que lugar as bonecas ocupam na vida de uma criança? De que forma elas operam na maneira como as meninas se relacionam com os próprios corpos e com os seus cabelos? Quais as implicações para uma menina "negra" que tem somente bonecas loiras disponíveis para brincar na constituição de sua própria identidade? Seria esse brinquedo também um objeto de criação de distinção "racial"? Para refletir sobre essas e outras questões nos debruçaremos sobre relatos de mulheres "negras" moçambicanas de classe média, coletados nos anos de 2011 e de 2015, residentes em Maputo. Além dos relatos dessas mulheres, trabalharei com um material coletado no grupo de discussão Carapinha do Indico ${ }^{3}$, de Moçambique, realizado no Facebook sobre estética "negra". Farei uma reflexão sobre a infância a partir da perspectiva de mulheres adultas. Trata-se, portanto, de um olhar em retrospectiva feito a partir de relatos e reminiscências de mulheres que já brincaram com bonecas, material da internet e pesquisa bibliográfica.

\footnotetext{
2 MANTOVANI, Flávia. "Nigeriano cria bonecas negras contra preconceito e supera venda de Barbie". G1. São Paulo, 28/08/2014. Disponível em: http://g1.globo.com/mundo/noticia/2014/08/nigeriano-cria-bonecasnegras-contra-preconceito-e-supera-venda-de-barbie.html. Acesso em 29/05/2016.

${ }^{3}$ O grupo Carapinha do Indico reúne mulheres "negras" e "mestiças" de Moçambique a fim de estabelecer elos sobre o cuidado com os cabelos na textura crespa. Carapinha é o nome dado ao cabelo crespo em Maputo (e também em algumas regiões do Brasil). Considerado um termo pejorativo, carapinha é positivado por essas mulheres que, agora, aprendem técnicas e cuidados com o cabelo crespo.
} 


\section{Apresentando o campo}

As mulheres que entrevistei em Maputo são de classe média, residem no Maputo Cimento 4 , são "negras" e "mestiças" e usam o português como língua correntemente falada. Elas, contudo, provêm de várias regiões de Moçambique. São elas: Pérola, Floyd, Agata, Sanzia e Salma. Foram para Maputo a trabalho. Pérola é da cidade da Beira - localizada no centro do país, é a capital de Sofala -, Floyd é de lhambane - região sul do país - e Salma, de Chimoio - região sul do país, capital do distrito de Manica. Pérola é professora de física em uma escola pública e mudou-se para Maputo com os pais na década de 1970, quando estes foram para lá trabalhar. Floyd nasceu em Inhambane, assim como seus pais. Foi para Maputo em 2003 para fazer o curso técnico de aduaneiros no Instituto Comercial de Maputo. Hoje tem residência fixa em Maputo e trabalha em sua área de formação. Salma nasceu em Chimoio e mudou, com a mãe, para Maputo, em 2004, para estudar.

Para compreendermos o contexto da pesquisa, é interessante apresentar um pouco do que é a cidade de Maputo. Fundada em 1782 para ser um entreposto comercial da colônia portuguesa, entre as décadas de 1960 e 1970, expandiu-se comercial e industrialmente, beneficiando-se do crescimento econômico que a colônia viveu. Devido à guerra civil que ocorria no interior do país (1976-1992), a cidade sofreu imenso afluxo de pessoas vindas do interior, à procura de emprego, segurança e alimentação, uma vez que as zonas rurais eram regiões com pouca ou nenhuma estrutura. Descrita como um mosaico multicolor e região de forte atração da população rural (Manuel COSTA E SILVA apud Cecília Castanheira BILALE, 1998), Maputo congrega pessoas de norte a sul do país e é o município mais populoso de Moçambique, com mais de um milhão de habitantes (BILALE, 1998). Possui a maior concentração urbana, apresentando elevados índices de desemprego e de trabalho informal. Apenas $11 \%$ da população trabalha no setor formal (Tereza Cruz SILVA, 2005).

Nas últimas décadas, Moçambique passou por significativas transformações socioculturais, sobretudo nas zonas urbanas. O fim do período socialista e o início da década de 1990 foram acompanhados pela introdução de reformas políticas e econômicas que reverberam nos modos de vida e na organização da população. As reformas políticas incluíram a transição de um governo socialista para um governo democrático multipartidário e a abertura para uma economia neoliberal, resultado de um ajuste estrutural modelado pelo Banco Mundial e pelo Fundo Monetário Internacional (ver Anne PITCHER, 2002). Linda Van de Kamp (2011) aponta que, nesse mesmo período, as mulheres passaram a ter maior participação no mercado de trabalho. Além disso, a implementação de estruturas sociais e democráticas e o aumento de organizações não governamentais com foco em direitos das mulheres permitiram maior acesso ao trabalho e à educação (KAMP, 201 1). Assim, um grupo crescente de mulheres, solteiras e casadas, ganhou maior independência financeira, transformando as configurações familiares. Contemporaneamente, as mulheres estão explorando novos estilos de vida e posições sociais. Além de novas oportunidades, as recentes configurações sociais estão provocando questionamentos, conflitos e incertezas em uma cidade que passa por mudanças significativas. Fruto de uma história que inclui o colonialismo português, o socialismo, a recente guerra civil e o neoliberalismo, Maputo é uma cidade permeada por visões de mundo distintas e múltiplas. É preciso compreender a cidade como mosaico multicultural e, além disso, constatar que o português, embora muito falado, não é a principal língua da cidade.

${ }^{4}$ Cidade cimento é o termo local para a região de Maputo que se contrasta com os bairros de caniço. Como bem traduziu Felícia, uma interlocutora por volta dos seus 35 anos, "os bairros de caniço são as favelas de vocês, a cidade de cimento é o asfalto". Vale pontuar que se trata de uma oposição entre estes dois espaços que é extremamente complexa e permeável. 


\section{Reminiscências acerca da infância}

Como pontuei anteriormente, este trabalho não resulta de uma reflexão feita a partir de observações etnográficas de crianças, mas a partir de reminiscências de mulheres adultas sobre as suas brincadeiras com as bonecas. Essa opção apresenta alguns desdobramentos metodológicos. No que se refere às experiências com a própria infância, podemos apontar alguns aspectos. Ao falarem de suas memórias, suas fabulações sofrem interferências de elaborações de uma fase adulta sobre a infância. Essa interferência, muitas vezes feita de maneira crítica, é fruto de um olhar adulto sobre uma infância. Um trabalho realizado com crianças traria outras perspectivas para pensar a relação das bonecas e suas subjetividades. Muitas vezes, a forma como as mulheres falavam da sua infância era algo idealizado, por meio de memórias seletivas. Não foi fácil acessar essa memória e deu-se com interlocutoras que conheci em 2011 e com as quais eu já tinha certa intimidade. As memórias seletivas, contudo, são reveladoras daquilo que é pertinente ao assunto em questão. O que fica de uma experiência com a infância e o brinquedo? Quais marcas do passado permanecem em suas memórias que merecem ser resgatadas em conversas e reflexões sobre o tema? São essas questões que aparecem como pertinentes neste texto. No futuro pretendo realizar pesquisas com crianças em uma perspectiva da antropologia da infância para elaborar um outro ponto de vista sobre o tema. Fica, portanto a questão: será que as histórias de vida contadas por adultos podem ser vistas como pontos de vista de uma criança? (Marianne GULLESTAD, 2005). Minha aposta é que não. Uma reflexão sobre a infância é realizada sob o ponto de vista adulto. O que não reduz os relatos das mulheres a algo falseável.

Gullestad (2005) aponta para o caráter construído da infância na vida de um sujeito. Fabular sobre a infância não seria menos construído do que realizar uma pesquisa com adultos sobre sua fase adulta. Assim, por serem imaginadas, elas não são menos "reais". Elas são um constructo - como seria um constructo toda e qualquer entrevista. Cabe ressaltar que a infância emergiu como tema importante para minhas interlocutoras. De acordo com elas, era na infância que se ouviam piadas sobre os seus cabelos, era nessa fase da vida que se viviam as angústias sobre seus corpos nas relações com suas bonecas e com as outras crianças. É na infância que elas se percebe(ra)m como vulneráveis a críticas sobre sua estética e deseja(ra)m alterar e mudar seus corpos. De acordo com Salma, uma interlocutora com aproximadamente trinta e três anos, hoje em dia ela está tranquila quanto ao seu corpo, aceita seus cabelos e não se importa com as críticas dos outros. Para ela, a fase adulta é uma fase de força, momento em que se superam as insatisfações que durante a infância eram vivenciadas com muito sofrimento. Agata, outra interlocutora, afirmou que é muito importante ter cuidado com aquilo que se diz para uma criança, porque o peso com que elas recebem as nossas falas pode ser absolutamente forte e maléfico. A infância foi uma fase importante para o que, hoje, são essas mulheres e pensar nesse momento da vida é revelador sobre a forma como elas se enxergam atualmente.

\section{O poder da Barbie: um pouco de sua história}

Como a maior parte das bonecas que minhas interlocutoras tiveram em sua infância era a Barbie, faz-se importante resgatar um pouco de sua história a fim de que nos inteiremos sobre como ela se tornou um dos brinquedos globalmente mais populares e vendidos. Criada em 1959 por Ruth Handler, irmã e sócia de um dos donos da empresa Mattel, as bonecas que as precederam nos Estados Unidos tinham feições, traços e personalidades infantis. Ruth Handler, ao observar as brincadeiras de sua filha, notou que ela criava 
situações em que suas bonecas eram protagonistas de histórias de adultos. Essa observação fez com que percebesse a existência de um nicho de mercado que poderia ser explorado pela empresa. A ideia de fabricar uma boneca na versão adulta não foi prontamente aceita por seu irmão, o qual se manteve reticente quanto à criação do brinquedo.

Em uma viagem à Alemanha em 1956, Ruth Handler, sabendo da existência da boneca Bild Lili, foi à sua procura. Lili, como era popularmente chamada, foi criada baseada em uma personagem popular que aparecia em uma história em quadrinhos desenhada por Reinhard Beuthin para o jornal Die Bild-Zeitung. A boneca representava uma mulher segura de si e que dispensava os homens para fazer suas atividades domésticas. Ruth Handler voltou para os Estados Unidos carregando consigo três Bild Lili com o propósito de dissuadir seu irmão a criar uma boneca adulta. Assim, a primeira Barbie foi fabricada pela Mattel e vendida nas versões loira e morena em 1959 visando o público infantil.

Desde então, especialmente nos Estados Unidos, a Barbie foi alvo de duras críticas, processos judiciais, opiniões controversas e intervenções por parte das demandas dos consumidores. Contudo, nunca deixou de ser fabricada e vendida em todo o mundo. Uma das críticas mais contundentes dos consumidores norte-americanos diz respeito às representações sobre a figura feminina que a boneca anuncia: muito magra, com um padrão de beleza loiro e "branco" na maioria das suas versões. Quando foi produzida na cor de pele negra, em 1967, foi criticada por manter traços brancos além de ter sido fabricada com cabelos lisos. Em 1992, a Mattel criou uma coleção em que as roupas da boneca tinham os dizeres "Eu amo shopping", "Será que um dia terei roupas suficientes?" e foi alvo de críticas de pais que consideravam que estavam passando mensagens de estímulo ao consumo desenfreado às crianças. Em 1997, a Barbie teve seu corpo remodelado: a partir de um reconhecimento da imagem anoréxica que poderia inspirar, sua cintura ficou menos fina do que nas coleções anteriores. Vemos, com essas mudanças, que a Barbie exerce sobre as crianças um poder e uma admiração que a faz ser uma das bonecas mais vendidas do mundo. Sua estética, apesar de ser alvo de críticas, poderia ser vista como um espelho para as crianças que brincam com ela.

É interessante observar que Ruth Handler criou a boneca ao observar o comportamento de uma criança. As brincadeiras da sua filha são reveladoras das fabulações que muitas crianças fazem durante as brincadeiras com bonecas. Seria a Barbie a projeção de uma vida adulta? Seria o brincar com a Barbie o desejo de uma criança em ser adulto? Seria, ainda, a criança urbana consome esse brinquedo como um vir a ser? A história da Barbie convoca essas e outras questões cujas respostas merecem um novo artigo, mas que apontam para a centralidade da brincadeira como uma invenção de um universo adulto.

\section{Reações à Barbie: a aparição de novas bonecas no mercado global}

Ao considerar o poder de influência que a Barbie possui sobre várias mulheres no mundo inteiro podemos observar uma recente e crescente reação à sua estética. Uma reportagem publicada no portal Geledés traz o seguinte título: “'Sua beleza reconhecida...' americana cria e vende Barbies afro pela internet" 5 . O site Natural girls and women united é de encher nossos olhos: são dezenas de bonecas - e um boneco - de cores de pele

\footnotetext{
5 “'Sua Beleza Reconhecida...' Americana cria e vende 'Barbies afro' pela internet”. Geledés. 13/10/2013. Disponível em: http://www.geledes.org.br/sua-beleza-reconhecida-americana-cria-e-vende-barbies-afro-pelainternet/. Acesso em 29/05/2016.
} 
diferentes e com variados penteados afro. São bonecas que apresentam um considerável sucesso de vendas. A artesã Karen Byrd compra bonecas brancas e as customiza, fazendoas negras com os cabelos na textura crespa. Ela revende as bonecas e entrega em vários países pelo correio. Sendo eu - a antropóloga e autora deste texto -, uma mulher "negra", adulta, casada, sem filhos - me achei no direito de refletir sobre o assunto uma vez que tive uma infância que me acompanha em memórias sobre minha experiência "racial". Retomando essa memória, fiquei pensando ainda sobre esse objeto boneca e recuei um pouco. Muitas críticas facilmente surgiram: "mas elas continuam magras", "elas são impecáveis", "são bonecas que impõem um outro padrão de beleza", "são adultas", "bemsucedidas". Sim, elas são "Barbies". E de uma Barbie é exatamente isso que esperamos. Mas essas reflexões iniciais, que podem parecer clichês de uma mulher engajada, preocupada em ser politicamente correta, não resultaram de um policiamento raso. Eu fiz um franco esforço para entender um pouco a minha infância desde que comecei a pensar nas bonecas e me questionei: existe uma relação afetiva com esse brinquedo? Existe uma identificação? Uma projeção, uma idealização? Se sim, por que a boneca deve continuar sendo magra e adulta? As crianças são um vir a ser? Um projeto de adulto? As bonecas seriam um objeto em que se espelhar?

O poder que a Barbie, assim como outras bonecas com outras estéticas, exerce sobre as crianças, em vários contextos, nos leva a refletir sobre essas questões. Não foi somente essa artesã que lançou Barbies afro para serem vendidas na internet. A jovem brasiliense Ingrith Calazans também customiza bonecas para comercializar. De acordo com uma entrevistada ao G1, ela afirma: "Fui à loja e me deparei com um monte de bonecas brancas, loiras, dos olhos azuis"6. Tal constatação levou-a a estilizar bonecas e vendê-las em Brasília. Há ainda uma nova marca de bonecas adultas criada pela modelo e empresária Mala Bryan, nascida em St. Lucia, no Caribe. Ela criou uma linha de bonecas "negras" com várias tonalidades de pele e texturas de cabelos para competir no ramo. Essa proliferação de bonecas "negras" é reveladora da necessidade de haver bonecas "negras" no mercado. É também uma resposta à supremacia da estética branca nas bonecas que estão disponíveis no mercado mundial.

O que significa essa proliferação mundial de bonecas de diversas estéticas? Entre outras coisas, reforça o poder que a boneca adulta exerce sobre as crianças; que boneca é um brinquedo muito desejado e, além disso, reflete a necessidade de outras estéticas se fazerem representadas. Reitera o desejo das crianças de fabularem com bonecas, o que remete ao universo adulto. Além disso, são muito desejadas por mulheres adultas que têm colecionado bonecas negras porque, em muitos casos, elas não tiveram quando crianças. Mulheres de diferentes idades estão querendo para si objetos que sejam espelho de sua estética e, ainda, contestem o modelo de beleza idealizado pela figura da Barbie. Isso revela que essas bonecas, além de representarem um importante poder e fascínio sobre as mulheres de vários lugares do mundo, compõem parte da subjetividade dessas mulheres. A esse respeito tecerei algumas considerações.

\section{Bonecas e subjetividades}

Minhas bonecas em geral eram loiras, Barbies e bonecas de pano que eu mesma fazia. Eu ficava sempre a trançar as bonecas, colocava mechas nelas e elas até mesmo perdiam cabelos de tanto que puxávamos os cabelos delas. E tinham as

- LUIZ, Gabriel "Jovem do DF customiza bonecas negras e critica setor de brinquedos". G1. 29/12/2015. Disponível em: http://gl .globo.com/distrito-federal/noticia/2015/12/jovem-do-df-customiza-bonecas-negrase-critica-setor-de-brinquedos.html. Acesso em 29/05/2016. 
bonecas de pano que eram da cor do tecido que tínhamos. Os cabelos eram de lá e a gente trançava os cabelos. Para saber se as bonecas refletiam a minha imagem eu teria que fazer uma terapia, mas eu acho que sim. (Agata, Maputo, 2015).

Eu me espelhava na minha boneca e pensava: Por que meu cabelo não é igual ao dela? Era triste isso. (Sanzia, Maputo, 2015).

Eu tinha bonecas negras e loiras. Mas as bonecas negras eram caras naquela época e não se tinha muito. Eu não acho que eu me espelhava nas bonecas não. Eu fazia as bonecas de um jeito totalmente diferente do que eu sou. Eu colocava anquinhas nelas, enchia, enchia, enchia de algodão. (Salma, Maputo, 2015).

As falas acima são transcriações ${ }^{7}$ de conversas informais que tive com minhas interlocutoras em Maputo quando realizei uma pesquisa entre mulheres "negras" e "mestiças" de classe média naquela cidade. Elas são reveladoras de várias facetas sobre as memórias e a relação que possuíam com as suas bonecas na infância. Agata me colocou diante de uma esfera interessante da brincadeira com as bonecas: uma subversão do hair play. De acordo com Deborah Grayson (1995), brinquedos como a Barbie e bonecas afins retratariam um modelo patriarcal e capitalista de produção do desejo. Segundo ela, a indústria de brinquedos valoriza o hair play, que é a ênfase na brincadeira com os cabelos das bonecas. Assim, a Barbie mais famosa da Mattel teria sido a Totally Hair Barbie que focava o penteado da boneca e teve um sucesso absurdo de vendas por causa dos seus longos e lisos cabelos. Essa Barbie poderia ter seus cabelos tingidos, cortados e mais cabelos aplicados em sua cabeça. Para Grayson (1995) a boneca produziria um efeito danoso para as crianças que brincam com os cabelos lisos da Barbie. Ela pode, inclusive, apontar para subversões que as crianças fazem ao brincar com essa boneca. Tingir os seus cabelos, transformá-la, daria margem para várias elaborações que fogem do objetivo primeiro de ser uma boneca forjada em um contexto patriarcal e capitalista. Esse fascínio em brincar com os cabelos das bonecas fez com que Agata os transformasse, subvertendo-os. Ela, embora tenha brincado com os cabelos de suas bonecas, fê-lo trançando-os, numa tentativa de deixar o brinquedo o mais próximo de sua estética. Mais próximo da sua realidade.

Retomando as relações que as mulheres estabelecem com suas bonecas vemos que o relato de Salma, por sua vez, é dissonante. Para ela, as bonecas representam um lugar de alteridade, pois não se via espelhada nas bonecas e confeccionava esse brinquedo à sua maneira "enchendo as anquinhas de algodão". Criava para si bonecas que tinham "corpos completamente diferentes do seu". Esse modo de brincar foge do padrão dos estudos sobre esse brinquedo que afirmam serem eles espelhos para as crianças e inspiram o desejo de ser adulto. Já para Sanzia, ter bonecas loiras e "brancas" significou um desconforto e um sofrimento. Olhava para suas bonecas e queria ser como elas. Como não correspondiam, desejava transformar o próprio corpo.

Desses testemunhos, o hair play de Agata apresenta um lugar especial no que diz respeito à importância que as tranças apresentam para as mulheres moçambicanas entrevistadas. É sobre a centralidade que as tranças ocupam na vida dessas mulheres que tratarei adiante.

\footnotetext{
7 O termo transcriação vem da teoria literária e pode ser usado em várias acepções. Utilizo-o aqui tal como definido por Thelma Médici Nóbrega (2006, p. 250): "De modo geral, o termo 'transcrição', como transformação do original, costuma ser confundido com 'tradução livre', adaptação ou paráfrase, a invenção de um poema a partir de outro." Ou seja, embora não se trate de um poema, houve reprodução das falas de minhas interlocutoras a partir da minha memória e anotação posterior no diário de campo.
} 


\section{O hair play e as tranças}

Uma vez que o hair play é parte das brincadeiras das mulheres entrevistadas, cabe contextualizar a importância das tranças para as mulheres moçambicanas que conheci. As tranças possuem, para elas, um valor especial. Para muitas mulheres moçambicanas o dia da trança - sábado pela manhã - é dedicado para o cuidado com o corpo e para o compartilhamento de conhecimentos, histórias, afetos e festividades. Geralmente nesse dia da semana as mulheres se reúnem em um quintal na área periférica da cidade para se adornarem e se trançarem. Escutam músicas como o zouk, o pop norte-americano e a morna cabo-verdiana. É um momento das mulheres, quando as outras preocupações ficam em segundo plano. Além disso, as técnicas para trançar são percebidas por muitas mulheres maputenses como um trabalho de arte. Poderíamos compará-lo ao trabalho de cestaria, pois, além de exigir uma habilidade específica, demora horas para ser concluído.

A produção dos cabelos exige um conhecimento específico, as habilidades precisam ser aprimoradas e apresentar uma estética admirável. Tal atividade é reconhecida localmente como expressão artística: "As mulheres daqui fazem verdadeiras obras de arte nas cabeças das pessoas", contou-me Lena, em 2011. As tranças simples, que envolvem mechas de cabelo divididas em três partes, entrecruzadas de forma intercalada, são aprendidas pela maioria das mulheres. Pérola, uma mulher por volta dos seus dezesseis anos, disse-me que aprendeu a trançar-se sozinha quando ainda era pequena, pois seus cabelos, muito volumosos, ocupavam horas dos dias de sua avó. Aquelas que têm curiosidade aprendem a elaborar as complicações que as cabeças das mulheres mais exigentes demandam, sendo reconhecidas pelas demais.

Em suas narrativas, as interlocutoras afirmam terem tido curiosidade em aprender e aprimorar sua técnica. Curiosidade, aqui, é o termo local para aquilo que funciona como o mote impulsionador do aprendizado das técnicas de pentear. Assim, estimuladas por essa curiosidade, muitas mulheres acabam trançando irmãs mais novas, amigas e vizinhas, expandindo sua fama de trançadeiras e sofisticando suas técnicas a partir da prática. Segundo apontam, é necessário persistir nas tranças, mesmo que no início elas não fiquem bem. Ser capaz de trançar bem, de fazer complicações nas cabeças das pessoas, era sempre algo mencionado como motivo de orgulho; não era raro que apontassem para a cabeça de alguma amiga e exclamassem: "Olha, fui eu que trancei ely", ou "Viu como ela está bonita? Fui eu que trancei a cabeça dela." Quando indagadas sobre esse processo criativo, elas me diziam:

Eu vou fazendo as tranças, aí eu penso, se eu puxar isso aqui para um lado vai ficar bonito. Se eu fizer para esse lado fica bem também. Se eu puxar uma para esse lado fica bonito. E assim vou fazendo essas complicações todas na cabeça. Vai ficando bonito. (Pérola, Maputo, 2011).

Complicações é o termo usado para se referir a um valor estético. Ter complicações na cabeça é possuir o penteado mais sofisticado, aplicar os cabelos mais longos, ter os cabelos tornados mais próprios. As complicações são, ainda, tramas que confundem aquele que vê quanto à maneira como foram realizadas. Elas parecem querer confundir o observador, uma vez que não se podem acompanhar os caminhos que as tranças percorreram para criar aquele efeito visual. Ademais, configura uma espécie de ostentação na cabeça, seja a partir do uso de extensões bem longas, seja pela exibição das complicações. A cabeça assume relevância em relação ao restante do corpo, chama a atenção para si. Tramas simples, embora comuns, transmitem a ideia de pouca elaboração, portanto, são menos apreciadas. Nesse sentido, trançar bonecas loiras denota uma 
subversão a uma estética imposta por um brinquedo comprado. Ao brincar de trançar, Agata quer tornar a boneca mais próxima de sua estética, transformá-la. Gostaria Agata de ver-se refletida sua imagem naquelas bonecas? Que transformação é essa a que ela quer submeter seu brinquedo para que ele faça sentido? O hair play que opera na minha interlocutora é o de singularizar. Ela se atreve a não aceitar a Barbie como algo que lhe é imposto e cria para si uma nova brincadeira.

Nos relatos recolhidos em Maputo, em conversas informais, pude perceber ainda o trabalho manual envolvido na confecção das bonecas. Como mencionado na transcriação acima, muitas bonecas dessas mulheres eram feitas por elas mesmas, com os materiais que dispunham. Fazer a boneca é uma atividade lúdica, pois os brinquedos criados não representam necessariamente a figura humana de maneira realista. Não ter a Barbie ou uma boneca que imite a figura humana estabelece na brincadeira com as bonecas uma relação de criatividade inventiva e não faz desse objeto um objeto-espelho tal como sugerido na indagação do título do meu texto.

A fala de Sanzia sobre os cabelos das suas bonecas possibilita algumas reflexões a esse respeito. Para ela, não ter os cabelos lisos era motivo de sofrimento e angústia. Nesse contexto, a boneca operaria como um objeto-espelho uma vez que a criança que foi Sanzia se via em suas bonecas desejando ter cabelos que ela não possuía "naturalmente". Sanzia me contou que, embora essa fosse uma questão bastante difícil durante sua infância, hoje vê esse ponto como algo superado. Ela usa perucas, extensões, mechas, tranças e o cabelo na textura crespa, estabelecendo com seu corpo um jogo de metamorfose comum entre as mulheres maputenses. É um símbolo de status para as mulheres em Maputo alternar seus penteados, fato visto como incomum entre as mulheres de Brasília onde também realizo pesquisa. Elas estão sempre mudando de penteado e esse valor, muitas vezes, reflete um desejo de ostentação, uma vez que cabelos custam muito caro. Além de sinônimo de status, a mudança compulsória de penteados, deixar os cabelos do mesmo jeito por muito tempo é algo criticado por outras mulheres.

Para ilustrar essa prática, relato a história de Paula, uma estudante da Universidade Eduardo Mondlane, de dezessete anos, quando me deu fotos de todos os penteados que ela já fez. Na seleção das imagens, há quarenta e quatro penteados feitos ao longo de dois anos. Seus cabelos já foram compridos até a altura do busto, com mechas de cabelos loiros; foram trançados junto do couro cabeludo com mechas loiras e pretas; já estiveram desfrisados com os cabelos na altura dos ombros; foram trançados em mechas ruivas; costurados em tissagem de cabelos lisos na altura do queixo; penteados no estilo $\mathrm{Jimi}^{8}$.

Não apenas Paula tem o hábito de registrar seus penteados: outras mulheres que conheci, sobretudo as mais jovens, adotam essa prática. A cada novo penteado, as mulheres se sentem como que renovadas e guardam expectativas de serem elogiadas por estarem com um visual completamente diferente. Sua postura corporal e feição mudam consideravelmente, consideram-se "uma nova mulher" com os novos cabelos. Os cabelos, assim, acabam alterando gestos e performances, direcionando as roupas que vão usar e até a forma de como se sentem. Paula destacou, em nossas conversas, que a mudança de cabelos implica mudanças nas maneiras de sentir-se:

Quando eu quero parecer mais angelical eu coloco cabelos cacheadinhos. Quando eu quero parecer mais mulher eu coloco cabelos mais longos. Se quero parecer mais séria, mais formal, eu uso cabelos ondulados. O Jimi eu faço quando eu me sinto mais rebelde. Eu gosto de brincar com isso! (Pérola, Maputo, 2012)

${ }^{8}$ O Jimi é um penteado onde se ouriça os cabelos formando uma espécie de coroa capilar. No Brasil é chamado de Black Power. 
Alterar os penteados em um curto período de tempo estabelece com o corpo uma relação que é localmente muito valorizada. O desejo de mudar sempre é reforçado pelo valor, comum entre as jovens, de marcar a diferença. Marcar a diferença não é somente seguir os penteados, guiando-se pela moda: faz parte do entendimento de que é preciso inovar, surpreender com um novo penteado, estar à frente das novidades, criar complicações na cabeça. Quando Paula comenta que, com o desejo de mudar, experimenta outras maneiras de ser, brinca com as possibilidades infinitas de tornar-se continuamente uma nova pessoa, a partir de novas atuações. À medida em que os cabelos alteram o corpo dessas mulheres de maneira radical e constante, transformando-as em "outras mulheres" - segundo suas próprias palavras -, percebemos uma forma de se relacionar com a estética da cabeça na qual o efêmero é fundamental e valorizado. Aquela que pode mudar seu penteado, atualizar-se, é tida como uma mulher de status e reconhecida por sua beleza. Seus corpos devem ser constantemente refabricados e reconstruídos, a fim de se tornarem femininos e belos.

Esse gosto pela mudança constante exige, naturalmente, um considerável estoque de cabelos disponíveis. É por isso que, entre as mulheres que conheci, uma prática de acúmulo de cabelos estava sendo cultivada. Idealmente, elas gostariam de ter todos os cabelos: curtos, longos, cacheados, ondulados etc. O modo de armazená-los exige conhecimento sobre sua conservação. Era comum haver uma maleta ou baú para guardálos. Além disso, não podem ser guardados de qualquer maneira.

Existe uma classificação para organizá-los: há os que são usados no dia-a-dia, pois que, além de darem um ar mais casual, não demandam tanto tempo para aplicar e não são tão "surpreendentes". Outros, reservados às festas, são guardados para serem usados somente em ocasiões solenes. Em geral, são mais suntuosos, maiores e inovadores. Há ainda as perucas que, menos comuns, são guardadas como possibilidade para serem acionadas no caso de um evento inesperado ou alguma emergência. Outra prática comum em relação aos cabelos é a troca entre amigas. Cabelos são objetos para presentear, comprando ou doando os próprios cabelos. A troca que pude observar se dava, em geral, entre mãe e filha, entre irmãs, e entre amigas mais próximas. Essa prática é importante porque cada vez que são retirados da cabeça eles perdem um pouco dos fios e, consequentemente, do volume, tendo uma durabilidade restrita à sua aplicação e circulação.

\section{Boneca: um objeto de afeto}

Uma vez que as tranças são práticas comuns entre as mulheres "negras" residentes em Maputo e sua confecção está envolvida de afeto - senta-se apoiando-se o corpo umas das outras, dedica-se muito trabalho e cuidado com o corpo alheio - vemos como o hair play é parte importante de uma dinâmica de brincadeiras que contribuem para a formação da subjetividade das mulheres moçambicanas entrevistadas. As bonecas, esses objetos de companhia para uma criança, podem ainda acompanhar a vida de uma mulher adulta sendo guardadas por muitos anos, mesmo depois da infância. Para as mulheres adultas entrevistadas, ficou latente o fato de que elas guardam para si as poucas bonecas negras que tiveram na infância. Esse objeto, geralmente infantil, desperta sobre elas, além de fascínio, uma relação de afeto que atravessa o tempo. Agata mostrou-me as bonecas negras que guardara para dar para sua filha caso venha a ter uma. Desfazer-se de outros brinquedos e não das bonecas é algo muito significativo. Ela guardava suas bonecas com grande afeto, como uma lembrança da infância, como uma relíquia rara e difícil de encontrar no mercado - objeto que merece ser mantido mesmo depois de tanto tempo.

Além de guardarem suas bonecas para presentearem a geração futura, muitas interlocutoras se referiam a elas como objetos de afeto. Walter Benjamin (2002) pondera 
como a boneca representa uma brincadeira que congrega, ao mesmo tempo, um jogo e um amor. Brinca-se como um objeto de companhia, um brinquedo que, além de funcionar como espelho, desperta projeções sobre uma vida adulta almejada, permitindo fabulações sobre o futuro. Quando uma criança brinca com sua boneca, penteia-a e lhe dá banho, constrói uma relação de afeto. Mais que um mero objeto utilitário, está imbuído de muitos significados.

Em campo, quando eu mostrei às minhas interlocutoras as bonecas negras estilizadas mencionadas anteriormente, elas ficaram fascinadas e cogitaram a possibilidade de colecioná-las. O poder e o fascínio sobre as bonecas adultas não atingem apenas crianças, mas também mulheres adultas. Entre os motivos desse fascínio é o fato de que elas não tiveram muitas bonecas negras na infância. Mas não apenas isso: as bonecas são realmente muito bonitas e interessantes. O sentimento despertado é de que agora poderão ter bonecas que se parecem com elas e, até mesmo, poderão colecioná-las.

\section{Considerações finais}

No intuito de esboçar alguns apontamentos para as perguntas anteriormente apresentadas, elaboro algumas considerações. Qual o lugar que a boneca ocupa na vida de uma criança? Essa não é uma resposta unívoca como vimos no decorrer do texto. Podemos sugerir que, muitas vezes, a boneca é um objeto afetivo que provoca certo fascínio na vida das mulheres ao rememorarem sua infância e que, sendo um objeto de afeto, implica consequências subjetivas em suas vidas adultas. As bonecas se apresentam, algumas vezes, como um objeto-espelho que reflete a imagem do que essas mulheres gostariam de ser e do corpo que gostariam de ter. Esse ponto é especialmente enfatizado na fala de Sanzia que se frustra por não ter cabelos lisos e longos como os das suas Barbies. Perguntei também se seria esse brinquedo um objeto de distinção "racial". Pude observar em campo que a construção da percepção "racial", entendendo "raça" em seus aspectos fenotípicos, parece ser construída antes mesmo de se brincar com as bonecas. Ao que tudo indica, as marcas de segunda pele e a aparência já são percebidas pelas crianças muito cedo e as bonecas vêm reiterar essa distinção.

Como vimos, as bonecas despertam um verdadeiro fascínio tanto na infância quanto na fase adulta de mulheres moçambicanas e de outras partes do globo. São fundamentais para a construção da identificação da criança com a imagem que se quer construir sobre si. Mas também são subvertidas quando não apresentam a mesma estética da criança que brincou com ela. Bonecas loiras do cabelo comprido são transformadas em brinquedos semelhantes às crianças, ou seja, com tranças. Como, por exemplo, quando Mena, uma interlocutora moçambicana, afirmou que, ao ver aquelas bonecas loiras, ela as trançava fazendo com que o brinquedo se parecesse com ela. Brinquedos constituem não somente réplicas de um mundo real como também revelam um pouco dos valores e das ideologias de uma cultura (Danielle Barbosa Lins de ALMEIDA, 2008). A proliferação de bonecas adultas com outras estéticas pelo mundo atesta a importância de construção de autoimagens diferentes daquela vendida pela Barbie: majoritariamente "brancas" e loiras. As crianças "negras" mundo afora querem consumir brinquedos que se pareçam com elas, o que é atestado pelo aparecimento de uma nova indústria de bonecas "negras" e por sua estilização. Ao que tudo indica muitas vezes as bonecas podem ser parte da representatividade para crianças em Maputo e alhures. 


\section{Referências}

ALMEIDA, Danielle Barbosa Lins de. "Beyond the playground: the representation of reality in fashion dols' advertisements". Linguagem em (Dis)curso, v. 8, n. 2, p. 203-228, maio/ago. 2008.

BENJAMIN, Walter. Reflexões sobre a criança, o brinquedo e a educação. São Paulo: Editora 34, 2002

BILALE, Cecília Castanheira. A mulher migrante na cidade de Maputo, a migração feminina interna, causas e consequências sócio-econômicas e demográficas. 1998. Dissertação. Maputo, Universidade Eduardo Mondlane, Faculdade de Letras e Ciências Sociais, Departamento de Geografia.

GRAYSON, Deborah. "Is it fake? Black Women's hair as spectacle and spec(tac)ular". Camera obscura: feminism, culture and media studies. Setembro 12 (3 36), p. 12-31, 1995.

GULLESTAD, Marianne. "Infâncias imaginadas: construções do eu e da sociedade nas histórias de vida”. Educ. Soc., Campinas, v. 26, n. 91, p. 509-534, Maio/Ago. 2005. Disponível em http://www.scielo.br/pdf/es/v26n91/a1 1v2691.pdf. Acesso em 29/05/2016.

KAMP, Linda Van de. "Converting the spirit spouse: the violent transformation of the pentecostal female body in Maputo, Mozambique". Ethnos: Journal of Anthropology, v. 76, Issue 4, p. 510-533, 2011.

NÓBREGA, Thelma Médici. "Transcriação e hiperfidelidade". Cadernos de Literatura e tradução, n. 7, p. 249-255, 2006.

PITCHER, Anne. Transforming Mozambique. The Politics of Privatisation, 1975-2000. Cambridge: Cambridge University Press, 2002.

SILVA, Tereza Cruz. A organização dos trabalhadores do sector informal dos mercados de Maputo e sua acção na promoção de melhores condições de vida e de trabalho: $O$ papel da Associação dos Operadores e Trabalhadores do Sector Informal - ASSOTSI. Genebra: Organização Mundial do Trabalho, 2005.

[Recebido em 02/05/2016 e aceito para publicação em 18/05/2016]

\section{Some Notes on Dolls for Black Women in Maputo}

Abstract: This essay is about the role played by dolls in the formation of subjectivity of Mozambican black women. Bearing in mind that the toy industry delivers a large production of white and blond dolls to children from diverse ethnic groups, we address the following issues: What is the role dolls play in the life of a child? How do they interfere in the way girls relate with their own bodies and their hair? What are the consequences to the subjectivity of a black girl of having solely white blond dolls to play with? Would this toy be, among other things, a factor in creation of racial distinctions? We will discuss childhood from the perspective of adult women. This essay is hence a retrospective study based on stories and reminiscences of women who played with dolls in their childhood.

Keywords: Dolls; Black women; "Race". 